\title{
Drought stress impact on leaf proteome variations of faba bean (Vicia faba L.) in the Qinghai-Tibet Plateau of China
}

\author{
Ping $\mathrm{Li}^{1,2,4} \cdot$ Yanxia Zhang ${ }^{3} \cdot$ Xuexia $\mathrm{Wu}^{1} \cdot$ Yujiao $\mathrm{Liu}^{1,2,4}$
}

Received: 20 June 2017 / Accepted: 4 January 2018 / Published online: 5 February 2018

(c) The Author(s) 2018. This article is an open access publication

\begin{abstract}
Water scarcity is a major abiotic stress factor that strongly influences growth, development and yield of grain legumes in arid and semi-arid area of the world. Drought stress frequently occurs during the seedling stage and finally affects yield of faba bean (Vicia faba L.). However, the responses of plant leaf to drought have not been documented very well at the proteomic level. "Ga da dou" of the drought-tolerant faba bean cultivar was exposed to drought to examine the proteome changes of leaves. In this study, 2-week-old seedlings were subjected to water deficit by 7 days drought stress, whereas control plants were regularly irrigated. After withdrawing water, plants exposed to drought for 7 days and control plants at the same developmental stage were included in quantitative proteomic analysis using two-dimensional electrophoresis gels of proteins in combination with mass spectrometry. Over 300 proteins were detected by 2-DE, 50 differentially expressed proteins were detected by $t$ test and 30 proteins were successfully identified by MALDI-TOF/TOF, in which 25 proteins were clearly downregulated and five proteins were upregulated. The quantified proteins were grouped into five functional groups, mainly regulatory proteins (46.7\%), energy metabolism (23.3\%), cell cytoskeleton (6.7\%), other functions (20\%) and unknown function (3.3\%). Chitinase was upregulated under drought, suggesting that it was an important part of the plant defense system, playing an important role in stress resistance. 50S ribosomal protein was upregulated under drought, suggesting its role in protecting plants against stress by re-establishing normal protein conformations. The abundance of proteins involved in protein synthesis such as chitinase, Bet protein and glutamate-glyoxylate aminotransferase was upregulated under drought stress. These proteins could play important roles in drought tolerance and contribute to the relatively stronger drought tolerance of "Ga da dou".
\end{abstract}

Keywords Faba bean $\cdot$ Drought resistance $\cdot 2$-DE $\cdot$ Proteome $\cdot$ Function

$\begin{array}{ll}\text { Abbreviations } \\ \text { 2-DE } & \text { two-dimensional gel electrophoresis } \\ \text { MALDI } & \text { matrix-assisted laser desorption/ionization } \\ \text { TOF } & \text { time-of-flight } \\ \text { TCA } & \text { trichloroacetic acid } \\ \text { BME } & \text { beta-mercaptoethanol }\end{array}$

Yujiao Liu

13997058356@163.com

1 State Key Laboratory of Plateau Ecology and Agriculture, Qinghai University, Xining, Qinghai, China

2 Qinghai Academy of Agricultural and Forestry Sciences, Xining, Qinghai, China

3 Rice Research Institute, Sichuan Agricultural University, Chengdu, Sichuan, China

4 Qinghai Research Station of Crop Gene Resource \& Germplasm Enhancement, Ministry of Agriculture, Xining, People's Republic of China

$\begin{array}{ll}\text { DTT } & \text { dithiothreitol } \\ \text { IEF } & \text { isoelectric focusing } \\ \text { IPG } & \text { immobilized pH gradient } \\ \text { SDS-PAGE } & \text { SDS-polyacrylamide gel electrophoresis } \\ \text { ACN } & \text { acetonitril } \\ \text { TFA } & \text { trifluoroaceticacid } \\ \text { NCBI } & \text { National Center for Biotechnology } \\ & \text { Information } \\ \text { kDa } & \text { kDalton }\end{array}$

\section{Introduction}

Water deficit and dehydration is one of the most important environmental stress factors that greatly influences plant growth and development and seriously reduces crop yield (Pandey et al. 2008; Ceccarelli 2010; Farooq et al. 2017) and it is the bottleneck of agricultural development in 
many regions. However, very few plants have subjected to biochemical and molecular studies to analyze the mechanisms of dehydration stress tolerance. They showed that the intrinsic ability of plants to tolerate various environmental stresses was a result of different biochemical and molecular mechanisms. What is more, elucidation of the nature of these mechanisms would be an interesting area of research. Many studies on the resistances of plants under water stress showed that plants can produce a series of changes in morphological, physiological, biochemical and molecular aspects and showed drought-resistant ability (Alam et al. 2010; Manaa et al. 2011; Chen et al. 2011; Gupta et al. 2014). Nowadays, with the rapid development of modern molecular biology, the mechanism of drought resistance in plants not only had great influence on it in terms of morphology and physiology but also genetic engineering had increased understanding (Zhu 2002; Chaves et al. 2009; Cramer et al. 2011). Since proteins are directly involved in the plant stress response, the response proteins induced by drought have already became a hot spot in fighting drought and gene expression adaptation to adverse arid circumstances (Watson et al. 2003; Zhang et al. 2006; Farooq et al. 2009; Azooz 2010; Kosová et al. 2011; $\mathrm{Xu}$ and $\mathrm{Wu}$ 2016). Legumes are valuable agricultural, commercial and cold-tolerant crops that serve as important nitrogen sources for human diet, animal feed and farmland (Broughton et al. 2003; Boschin and Arnoldi 2011). Particularly, changing in proteomic expression during drought stress had been observed in legume crops showing differential regulation of mechanisms, such as chick pea (Turner et al. 2005; Subba et al. 2013; Jaiswal et al. 2014), soy bean (Tran and Mochida 2010; Das et al. 2016) and mung bean (Sengupta et al. 2011). They showed that the intrinsic ability of model legume plants to tolerate various environmental stresses was a result of different biochemical and molecular mechanisms.

Faba bean (Vicia faba L.) is one of the most important legume species for human consumption due to its highnutritional value, high protein content and beneficial healthy properties (Amede et al. 1999; Abdelmula et al. 1999). Qinghai is located in northwest China and on the northeastern part of the Qinghai-Tibet Plateau with an average altitude above $3000 \mathrm{~m}$. Faba bean could adapt to the cold climate and varied land conditions. Faba bean can product rhizobia nitrogen symbionts for itself and succession crop as nitrogen sources and it could change soil structure. In Qinghai, $80 \%$ of the faba bean is distributed in the irrigated agriculture region which accounts for only $30 \%$ of the total cultivated land biome; however, $70 \%$ of the total cultivated land is a rain-fed land (dry areas or semi-arid areas) where the planting area of faba bean accounts only for $20 \%$. Faba bean uses more water and more sensitive to drought than some other grain legumes such as common bean, pea and chickpea (Mittler and
Zilinskas 1994; Martínez et al. 2007; Awasthi et al. 2014). Drought stress can lead to serious yield decrease of faba bean in arid area and affects the efficient and sustainable development of agriculture in Qinghai.

It is imperative for breeding drought-resistant cultivars to identify the molecular mechanism that improves adaptation to water-limited environments (Zhang et al. 2015). The aims of this study were to increase understanding of the molecular mechanisms of the response to drought stress in faba bean using a proteomic approach. A combination of two-dimensional gel electrophoresis and matrixassisted laser desorption ionization-tandem time-of-flight (MALDI-TOF/TOF) was used to identify the changes of leaf proteome in the seeding stage under drought stress. Since drought stress frequently occurs during the seedling stage, especially at the early stages, and deleteriously affects the growth of faba bean and reduces yield all over the world (Khan et al. 2010). Our research focused on seeding stage of the cultivar "Ga da dou", which has a better drought-tolerant ability in our previous study (Li et al. 2015), drought-related proteins were identified in the leaf and possible roles of those proteins in drought-response mechanism were discussed. The objectives of this study were to provide technical support and theoretical basis for drought tolerance in faba bean and to explore relationships among potentially useful traits in breeding programs for drought tolerance.

\section{Materials and methods}

\section{Plant materials, growth conditions and dehydration treatment}

The experiments were conducted in 2015 and 2016. Seeds of faba bean (Vicia faba L.) "Ga da dou" were selected for this study based on the previous findings from our laboratory (Li et al. 2014; Hou et al. 2015). Seeds were surface-sterilized by soaking in 5\% (v/v) sodium hypochlorite solution for $10 \mathrm{~min}$ followed by three sterile distilled water washes and soaked for 1 day; germinated seeds were sowed in pots containing a mixture of soil and vermiculite $(1: 2$, w/w; five plants $/ 2.0 \mathrm{~L}$ capacity pot with $18 \mathrm{~cm}$ diameter) in an environmentally controlled growth room. The seedlings were maintained at the temperature of $25 / 18{ }^{\circ} \mathrm{C}$ (day/ night), relative humidity of $70 \pm 5 \%$, and a $16 \mathrm{~h} / 8 \mathrm{~h}$ (day/ night) photoperiod $\left(250 \mu \mathrm{mol} / \mathrm{m}^{2} / \mathrm{s}\right.$ light intensity). The pots were provided with $100 \mathrm{~mL}$ of water twice daily that fully ensured normal growth. Two-week-old faba bean seedlings were subjected to withdrawing water for 7 days; leaf samples were collected and were instantly frozen in liquid nitrogen and stored at $-80^{\circ} \mathrm{C}$ for proteomics analysis. 


\section{Protein extraction}

Protein from two types of samples, normal water supply condition (control) and drought condition (drought treatment), from leaves were frozen in liquid $\mathrm{N}_{2}$ and ground in their frozen state in a chilled pestle and mortar to a well-ground powder. The powder was extracted with TCA/acetone precipitation and fractionation, based on the procedure reported by Shah et al. (2011) with some modifications. $2 \mathrm{~g}$ of powder was extracted with fifty volumes of $10 \%(w / v)$ TCA in acetone containing $0.07 \%$ 2-BME, and left overnight at $-20{ }^{\circ} \mathrm{C}$. The mixture was been centrifuged at $20,000 \mathrm{rpm}$ for $20 \mathrm{~min}$ at $4{ }^{\circ} \mathrm{C}$ and the pellet was washed twice with cold acetone containing $0.07 \% \mathrm{BME}$; intervals between centrifuges were $20 \mathrm{~min}$ at $-20^{\circ} \mathrm{C}$. The pellet was washed three times with $90 \%$ cold acetone containing $0.07 \%$ BME. The sample powder was then dried under room temperature for $1 \mathrm{~h}$, then solubilized in lysate buffer [8M urea, $2 \%(\mathrm{v} / \mathrm{v})$ Triton X-100, $60 \mathrm{mM}$ DTT] and left at $23{ }^{\circ} \mathrm{C}$ for $2.5 \mathrm{~h}$. The mixture was centrifuged at $12,000 \mathrm{rpm}$ for $15 \mathrm{~min}$ at $4{ }^{\circ} \mathrm{C}$ and the supernatant was collected with the help of a Pasteur pipette as the protein sample.

\section{Protein assay}

Protein concentration was measured by the Bradford (1976) method using bovine serum albumin as a standard according to the manufacturer's instructions. In total, three biological repeats were analyzed.

\section{2-DE and gel analysis}

Two-dimensional gel electrophoresis (2-DE) was performed according to the Amersham Biosciences handbook (2-D Electrophoresis using Immobilized $\mathrm{pH}$ Gradients, Amersham Biosciences, Piscataway, NJ, USA) and the procedure was developed by Görg et al. (2004). Before 2-DE, protein samples were incubated in hydration solution lysate buffer (7M urea, 2M thiourea, 4\% CHAPS, $65 \mathrm{mM}$ DTT, 0.2\% IPG buffer, $0.001 \%$ (w/v) bromophenol blue, $0.001 \%$ Pharmalytes pH 3-10). All the isoelectric focusing (IEF) steps were conducted at $20{ }^{\circ} \mathrm{C} ; 900 \mu \mathrm{g}$ and a volume of $350 \mu \mathrm{L}$ of proteins were loaded on to a $17 \mathrm{~cm}$ long immobilized $\mathrm{pH}$ gradient (IPG) strip with a non-linear $\mathrm{pH}$ gradient ranging from 3 to 10 in the first dimension. After rehydration, focusing was done on Ettan IPGphor under the following conditions: 50 V Rapid 14:00 HH:MM, 250 V Linear 2:30 HH:MM, 1000 V Rapid 2:30 HH:MM, 9000 V Linear 5:30 HH:MM, 9000 V Rapid 85,000 Volt Hr, 500 V Rapid 24:00 HH: MM. Then, strips were equilibrated in a buffer containing $6 \mathrm{M}$ urea, $2 \%(\mathrm{w} / \mathrm{v})$ SDS, $0.375 \mathrm{M}$ Tris-HCl, pH8.8, 20\% (v/v) glycerol, 1\% (w/v) DTT for $15 \mathrm{~min}$ in the same buffer but with $4 \%(\mathrm{w} / \mathrm{v})$ iodoacetamide replacing DTT. Following
SDS-PAGE in the second dimension, using homogeneous $12.5 \%$ SDS-PAGE gel, the temperature was maintained at $20{ }^{\circ} \mathrm{C}$. Electrophoresis was carried out at $50 \mathrm{~V}$ for $1 \mathrm{~h}$ and then at $200 \mathrm{~V}$ until the dye front was approximately $1 \mathrm{~mm}$ from the bottom of the gel. Protein spots in 2-DE gels were stained with Coomassie Brilliant Blue (CBBG-250) as previously described (Millar et al. 2001). Three replicate gels were used as controls and dehydrated. The experiment was repeated three times.

The gels were been scanned by an image scanner (GS-800 calibrated densitometer) in transmission mode and analyzed with the UMAX Magic Scan V6.0 software package (GE Healthcare/Amersham Biosciences). Brightness and contrast were set to default levels. All gels were scanned at 300 dpi resolution and saved as a grayscale TIFF file. The gel images were analyzed using PDquest 8.0.1 software and the gel loaded with control samples was selected as the reference gel. Technical variation between the plants was likely to be greatest in the system, and so proteins were considered to be differentially expressed if the paired $t$ test analysis was significant at the $p<0.05$ level (Owiti et al. 2011; Ge et al. 2013). The same pattern of change was observed for a given protein in all three biological repeats. Spot volumes were normalized by the total spot volumes per gel to avoid experimental variations among 2-D gels; at the same time, all spots were manually inspected and edited as necessary to verify the autodetected results. A spot abundance ratio of $>2.0$ or $<0.5$ was set as a threshold to identify differentially expressed proteins in this study and those proteins were excised from the gel using a cut $200 \mu \mathrm{L}$ pipette tip, and stored in a $500 \mu \mathrm{L}$ centrifuge tube at room temperature for 1 week or $-80^{\circ} \mathrm{C}$ for 6 months prior to MS identification.

\section{In-gel digestion and MS identification of proteins}

Using a protocol modified from that reported by Katayama et al. (2001), we excised selected protein spots from preparative gels, washed them with $100 \mu \mathrm{L}$ of distilled water and incubated twice (10 min each). We removed the water and destained the gel spots with CBB destaining solution at room temperature for $30 \mathrm{~min}$. Each piece of gel containing protein had the dehydrated solution and removed three times (30 min each) by $50 \% \mathrm{ABC} / 50 \% \mathrm{ACN}$ at $37{ }^{\circ} \mathrm{C}$. After the solution was removed, $10 \mu \mathrm{L}$ of working solution $(0.02 \mathrm{mM}$ trypsase of $25 \mathrm{mM} \mathrm{ABC/10 \%} \mathrm{ACN}$ ) was added to the pieces for $30 \mathrm{~min}$ and then they were covered with cover solution for digestion overnight (about $16 \mathrm{~h}$ ) at $37^{\circ} \mathrm{C}$. Afterward, the supernatants were transferred into another tube and added to $50 \mu \mathrm{L}$ protein extracting solution $(0.1 \% \mathrm{TFA} / 67 \% \mathrm{ACN})$ to the gel at $37{ }^{\circ} \mathrm{C}$ for $30 \mathrm{~min}$ and then centrifuged for $5 \mathrm{~min}$. The supernatant was dried under vacuum centrifugation for analysis by MALDI time-of-flight (TOF)/TOF on a mass spectrometer. 
The samples were digested with $5 \mu \mathrm{L} 0.1 \% \mathrm{TFA}$ followed by mixing in a 1:1 ratio with a matrix consisting of a saturated solution ( $\alpha$-cyano-4-hydroxy-trans-cinnamic acid in $50 \%$ ACN/0.1\% TFA); $1 \mu \mathrm{L}$ samples were spotted onto an ABI5800 Proteomics Analyzer MALDI-TOF/TOF system instrument (Applied Biosystems, Framingham, MA, USA). Data were acquired in a positive MS reflector using a CalMix 5 standard to calibrate the instrument (mass range $\mathrm{m} / \mathrm{z}$ 800-3500); both the MS and MS/MS data were integrated and processed using GPS Explorer V3.6 software (Applied Biosystems, USA) with default parameters. Data from MALDI-TOF/TOF were searched using MASCOT (http:// www.matrixcsience.com, Matrix Science, London, UK) and all searches were successfully identified based on $95 \%$ or higher confidence interval of their scores in the MASCOT V2.3 search engine (Matrix Science Ltd., London, UK), using the following search parameters: NCBInr databases "viridiplantae" (green plants 247882 sequences) were selected for the taxonomic category; trypsin as the digestion enzyme; one missed cleavage site; fixed modifications of carbamidomethyl (C); partial modifications of acetyl (protein N-term), deamidated (NQ), dioxidation (W), oxidation $(\mathrm{M}) ; 100 \mathrm{ppm}$ for precursor ion tolerance and 0.3 Da for fragment ion tolerance. All positive protein individual ion scores $>34$ indicating identity or extensive homology $(p<0.05)$ were considered successful. Functional categories were been assigned according to biological process, based on the SWISS-PROT/TrEMBL and UniProt protein databases. Faba bean is a non-model plant, so we mapped it to a model plant, Arabidopsis thaliana, for subsequent bioinformatics analysis. Firstly, gene ontology (GO) annotation defined each different protein by biochemical process, molecular function and cellular components (Banci et al. 2011) by the DAVID database (http://david.abcc.ncifc rf.gov). Secondly, KEGG provided a reference knowledge base through the process of pathway mapping according to the change of expression quantity for proteins (Kanehisa et al. 2008).

\section{Results}

\section{Proteomics map of faba bean leaf}

Plants respond and adapt to such drought stress by altering gene expression and activating various defense mechanism. In this research, we selected the 7 days drought stress treatment to analyze proteins from faba bean leaves to better show the protein for drought resistance. Total protein of leaves was extracted using a fractionation method (Shah et al. 2011); the protein concentration for the drought stress treatment was $6.01 \mu \mathrm{g} / \mu \mathrm{L}$, and for normal conditions was $6.75 \mu \mathrm{g} / \mu \mathrm{L}$. The overall protein profile and purity of the protein extraction were demonstrated by SDS-PAGE $(12.5 \%$ polyacrylamide gel) analysis. For detection of clearer bands, the result was positive; those were offered for the next studies of formulation and preparing technology for 2-DE. Total soluble protein $(900 \mu \mathrm{g}, 350 \mu \mathrm{L})$ was separated by IEF on an IPG strip (17 cm with $\mathrm{pH} 3.0-10.0$, non-linear gradient) in the first dimension and by $12 \%$ SDS-PAGE gel in the second dimension to separate the total protein for normal and drought stress treatments (Fig. 1). More than 300 protein spots were detected on gels of $\mathrm{pH} 3-10$, and quantitative analysis using PDquest 8.0.1 identified 50 that were significantly changed in abundance (paired $t$ test, $p<0.05$ ) during drying. To achieve a higher identification rate, trypsin digest fragments were subjected to MALDI-TOF/ TOF analysis, from which 30 protein spots were identified

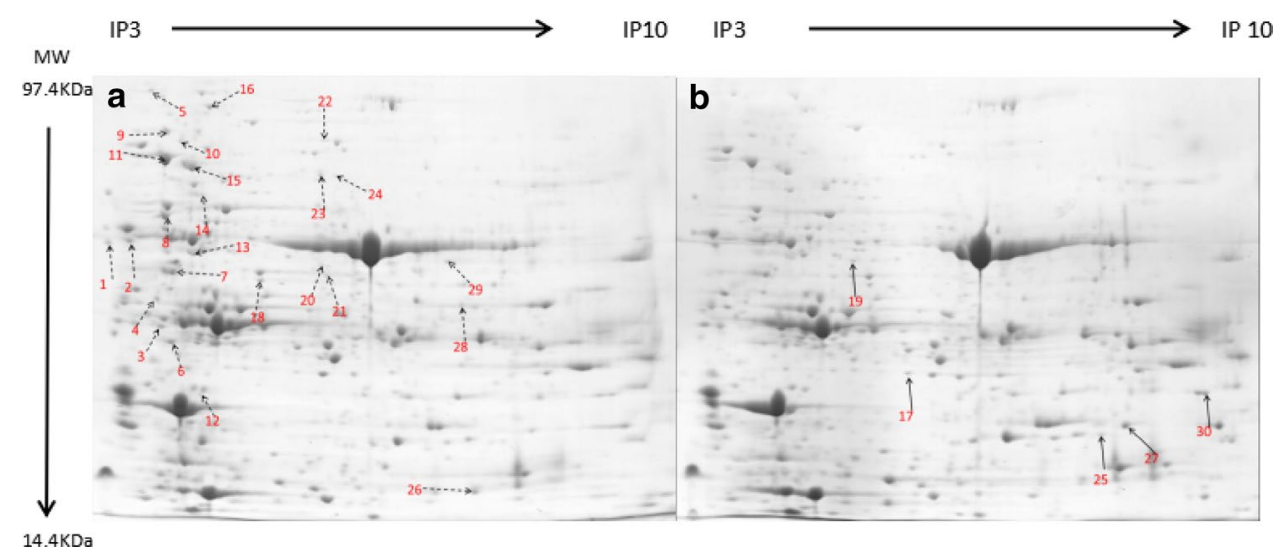

Fig. 1 Coomassie brilliant blue-stained 2-DE gel of proteins extracted from faba bean leaves grown under drought stress (right) and control (left) conditions. The 2-DE gel pattern was achieved through the optimized IEF methods using $17 \mathrm{~cm}$ strips with a narrow no-linear range ( $\mathrm{pH} 3-10)$. The horizontal dimension represents
$\mathrm{pH}$ distribution of proteins across the width of the gel; the vertical dimension refers to the molecular mass of proteins, as indicating by molecular weight markers on the right side. The downregulated spots are labeled in picture $\mathbf{a}$ and the upregulated spots are labeled in picture $\mathbf{b}$ 
successfully except two protein spots which failed to be identified (Table 1). This was the most obvious changed in trend for successfully identifying proteins by isoelectric point and molecular weight (Fig. 2). There was no distribution of proteins at isoelectric points 3.0-4.0; however, the number of protein spots was highest at 5.0-6.0, accounting for $50 \%$ of the total different proteins. The number of different proteins was the same between 4.0 and 5.0 and 6.0-7.0 and 7.0-8.0 and 8.0-9.0, accounting for 16.67 and $6.67 \%$, respectively, of the total different proteins. The molecular weight distributions had greater differences; as the molecular weight increased, the number of different proteins gradually reduced. The greatest number of different proteins was in the $30-50 \mathrm{kDa}$ range which accounted for $46.7 \%$ of the total different proteins, while just $10 \%$ were in the range 80-100 kDa.

\section{Protein identification}

Peptide mass fingerprinting data searches of 30 differentially expressed proteins were conducted with MASCOT search tools in NCBInr; 25 proteins were clearly downregulated, accounting for $84.4 \%$ of differences in total protein. Among those, under drought stress treatment proteins $5,7,14,15$, 24 and 29 were downregulated three times more than with normal water supply. Five proteins (17, 19, 25 and 30) were upregulated, accounting for $15.6 \%$ of differences in total protein; what was more, two proteins, 19 (8214) and 25 (5708), were newly appeared (Fig. 3). At higher points of protein homology, the sequence coverage rate is higher and the function of the protein points and homologous proteins was similar; our research showed that these protein points had higher homology with multiple types of leguminous plant protein sequences, with 30 proteins representing 28 kinds of protein or peptide sequence. Those proteins $(1,4,9,16,17$, 19, 21, 23, 24, 25) had homology with Medicago truncatula protein sequences, of which spot 25 had the highest homology at $35 \%$, and spots 1 and 24 the lowest at only $7 \%$. Protein spots 2, 11, 14, 15, 18 and 28 had homology with Pisum sativum protein sequences, of which spot 18 had the highest homology at $39 \%$. At the same time, spot 26 had the highest homology (19\%) with Cicer arietinum, spots 3, 13 and 30 had homology with soybean, spot 27 had homology with Galega orientalis and the rest of the proteins had homology with non-legume plants such as Trifolium pretense and Taxus cuspidate.

\section{Drought-expressed proteins}

Of all the differentially expressed proteins identified, 30 can be assigned to five functional classes: regulatory proteins, metabolism and energy, cytoskeleton, other functional proteins and unknown function (Fig. 4). Among those identified proteins, the major functional category corresponded to proteins involved in regulatory functions (46.7\%), and the second most abundant were those involved in metabolism and energy (23.3\%); proteins of unknown function accounted for only a small fraction of the total $(3.3 \%)$. From the function classification, we could see that the downregulated proteins had a connection with stress defense, metabolism and energy, cytoskeleton and redox homeostasis; at the same time, the upregulated proteins were involved in protein folding, aggregation and the photosynthetic system.

According to the mass spectrum results of the differential protein points, a library search of GO enrichment analysis was carried out to retrieve IDs of proteins homologous to the model plant Arabidopsis thaliana (Fig. 5). Through analysis we found that the 30 differentially expressed proteins were involved in 51 biological processes, such as single-organism biosynthetic processes (56\%), organic acid metabolism (46\%), pigment biosynthesis (50\%), organic compound metabolism (42\%), organic compound biosynthesis (59\%), cell macromolecule metabolic processes $(66 \%)$, cell biosynthesis (55\%) and macromolecule metabolic processes (65\%). Enrichment analysis of cellular localization discovered that the 30 differentially expressed proteins were located in seven cell locations: thylakoids, cytoplasm, organelles, intracellular organelle parts, ribonucleoprotein complexes, envelopes and proteasome core complexes. Among them, those in the cytoplasm, organelles and intracellular organelles showed protein enrichments of $93.3,61.9$ and $89.2 \%$, respectively. Enrichment analysis of molecular function discovered that the 30 proteins performed functions in binding with unfolded proteins, preproteins, nucleoside phosphate nucleosides, ribonucleotides, chitin, heat shock protein and transferase enzymatic activity, anion coordination and isomerase enzymatic activity. The enrichment of those involved in nucleoside phosphates and nucleotides was $38.2 \%$, of those involved in nucleosides and ribonucleotides was $31.1 \%$ and those participating in the enrichment of anionic coordination of proteins were $34.6 \%$.

\section{Discussion}

Proteins are an important product of gene expression, drought stress inhibits or induces expression of a large number of genes. 2-DE using the isoelectric point and molecular weight of different characteristics to separate thousands of proteins is a very good method (Celis and Gromov 1999; Görg et al. 2004) which has developed into separation of a complex protein mixture, and it is a core technology in most proteome researches. In this study, two-week-old faba bean seedling were subjected to 7 days dehydration by withdrawing water and total soluble protein were extracted using twodimensional gel electrophoresis. We identified more than

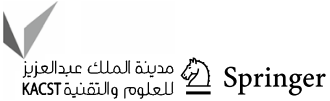


Table 1 Differentially expressed proteins identified by MS/MS

Spot no. NCBI accession no. Protein identification and species

Protein MW pI Sequence

Score emPAI Specificity D:C coverage

(\%)

A, downregulated protein spots

Regulatory proteins

2 gil1778378

$3 \quad$ gil734417431

$4 \quad$ gi|922380585

9 gil922328245

$10 \quad$ gil84468292

11 gil399942

14 gil12585295

$18 \quad$ gil37051117

20 gil502089910

$23 \quad$ gil357481949

$24 \quad$ gil357481949

Metabolism and energy

5 gil702278592

6 gil597305952

$8 \quad$ gil 84468288

$16 \quad$ gil922402067

$22 \quad$ gil525345100

$26 \quad$ gil502090577

$28 \quad$ gil3915699

Cytoskeleton

$\begin{array}{ll}13 & \text { gil734424370 } \\ 15 & \text { gil473217 }\end{array}$

Other functional proteins

1 gil35745628

$7 \quad$ gil593263764

12 gil567179243

$29 \quad$ gil 84468428
NAP1Ps (Pisum sativum)

$31 \mathrm{kDa}$ ribonucleoprotein, chloroplastic (Glycine soja)

Hydroxyproline-rich glycoprotein family protein (Medicago truncatula)

Heat shock protein 81-2 (Medicago truncatula)

Putative heat shock protein 81-2

Stromal $70 \mathrm{kDa}$ heat shock-related protein, chloroplastic; flags: precursor (Pisum sativum)

Phosphoglucomutase, chloroplastic (Pisum sativum)

S-adenosylmethionine synthetase-2 (Pisum sativum)

ERBB-3 binding protein 1-like isoform X1 (Cicer arietinum)

Stress-inducible protein, putative (Medicago truncatula)

Stress-inducible protein, putative (Medicago truncatula)

Glucosidase 2 subunit beta-like

D-Alanyl-D-Alaninecarboxypeptidase/D-Alanyl-D-Alanine-endopeptidase (Mycobacterium cosmeticum)

Putative RuBisCO subunit binding protein alpha subunit [Trifolium pratense]

ATPase, AAA-type, CDC48 protein (Medicago truncatula)

5-methyltetrahydropteroyltriglutamatehomocysteine methyltransferase-like (Cicer arietinum)

Carbonic anhydrase, chloroplastic isoform $\mathrm{X} 1$ (Cicer arietinum)

Glycine cleavage system T protein (Pisum 44.66 sativum)

73.13

48.78

61.24

90.51

84.60

37.49

41.91

$4.34 \quad 15$

5.927

$5.82 \quad 11$

$5.06 \quad 10$

5.1619

$5.22 \quad 21$

5.863

$6.27 \quad 39$

6.1314

$5.70 \quad 10$

5.707

\begin{tabular}{ll}
$4.61 \quad 4$ \\
\hline
\end{tabular}

$\begin{array}{ll}5.02 & 0.03\end{array}$

$5.20 \quad 24$

$5.07 \quad 14$

$6.01 \quad 13$

$7.04 \quad 19$

$8.79 \quad 13$

50.29

71.36

\begin{tabular}{ll}
$4.96 \quad 21$ \\
\hline
\end{tabular}

$5.01 \quad 14$

28.69

Hypothetical protein MTR_3g013460 (Medicago truncatula)

Hypothetical protein

PHAVU_010G016000 g (Phaseolus vulgaris)

52.43

4.537

$5.23 \quad 15$

$5.66 \quad 18$

$412 \quad 1.23 \quad 2.22: 1$

(Eutrema salsugineum)

Hypothetical protein
39.17

7.667

$127 \quad 0.16 \quad 2.01: 1$ 
Table 1 (continued)

Spot no. NCBI accession no. Protein identification and species

Protein MW pI

Sequence coverage

$(\%)$

Unknown function

21

gil217072432

Unknown (Medicago truncatula)

43.19

5.6823

$354 \quad 0.67$

$2.46: 1$

B, upregulated protein spots

Regulatory proteins

$\begin{array}{ll}25 & \text { gil357517981 } \\ 27 & \text { gil33414052 } \\ 30 & \text { gil356531651 }\end{array}$

Proteasome subunit alpha type-7-A protein (Medicago truncatula)

Class Ia chitinase (Galega orientalis)

27.27

$6.97 \quad 35$

$599 \quad 2.33 \quad 0.37: 1$

50S ribosomal protein L1, chloroplastic

35.99

$8.05 \quad 10$

$216 \quad 0.39$

$0.47: 1$

(Glycine max)

Other functional proteins

$\begin{array}{ll}17 & \text { gil} 922383823 \\ 19 & \text { gil357485703 }\end{array}$

Allergenic isoflavone reductase-like protein

Bet protein (Medicago truncatula]

38.09

9.2512

$404 \quad 0.82 \quad 0.35: 1$

gil 357485703

Glutamate-glyoxylate aminotransferase (Medicago truncatula)

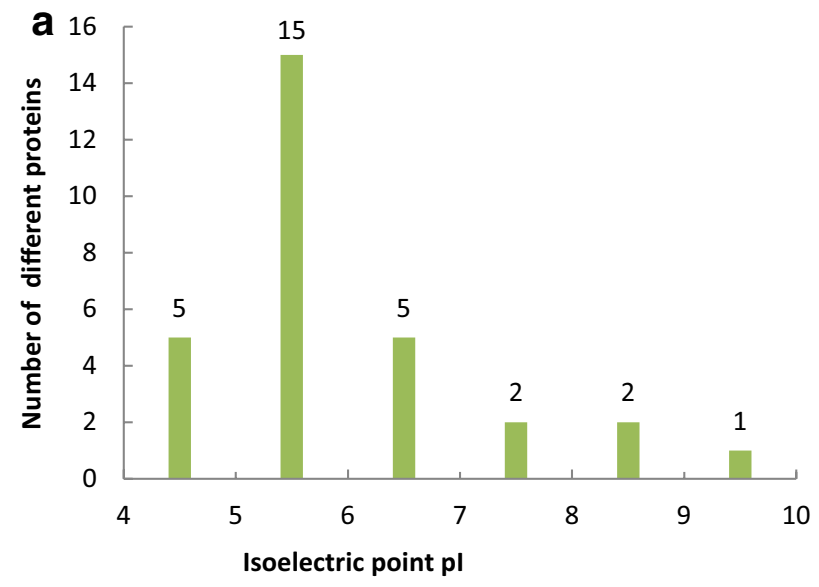

300 protein spots in gels of $\mathrm{pH} 3-10$. About 32 spots of differential expressed proteins were analyzed by MALDI-TOF/ TOF, and 30 spot proteins were identified successfully. We revealed that the isoelectric point and molecular weight of those differential proteins were focused on 5.0-6.0 pI (50\%) and $30-50 \mathrm{kDa}$ range $(46.7 \%)$; it was clearly found in the gels. In all 30 identified proteins, 25 spots were downregulated and five spots were upregulated. The number of downregulated proteins was greater than upregulated proteins for drought treatment relative to normal water conditions. It indicated that synthesis of some proteins was inhibited to improve adaptability to the environment under drought stress. The expression of some proteins increased (spots 17, 27 and 30) and some new proteins were induced (spots 19 and 25), so the ability of plants to tolerate drought could be improved. In general, the protein levels tended to decrease in response to drought stress.

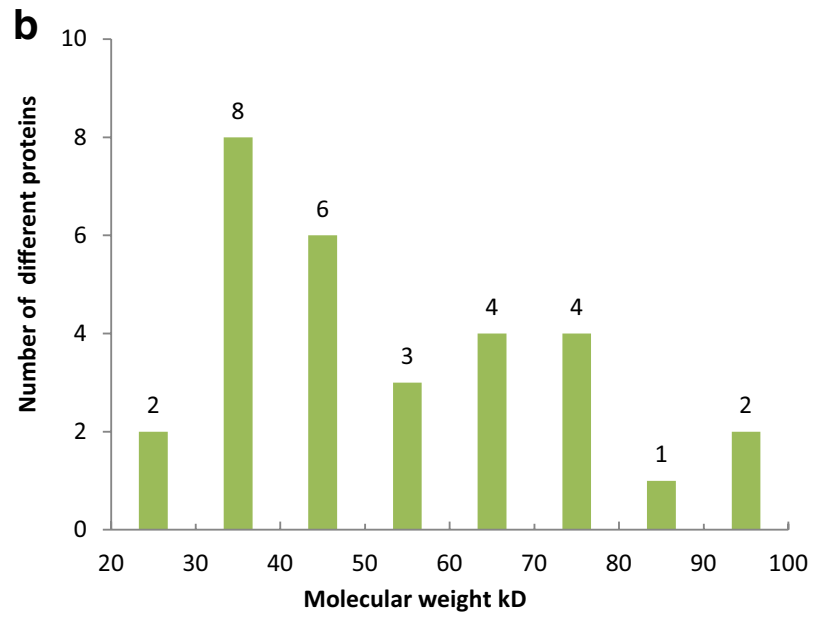

Fig. 2 Distribution of $\mathrm{pI}$ and molecular weight of different proteins in leaves. The isoelectric point is shown in a and the molecular weight is shown in $\mathbf{b}$

\section{Regulatory proteins}

The 30 protein spots were sorted into five types of functional category according to metabolic pathways and biological processes. Of them, regulatory proteins $(46.7 \%)$ constituted one of the biggest categories. Nucleic acid processing was an important regulation mechanism, and even more nucleotide processing was a key regulatory mechanism. It showed in the cellular component enrichment analysis that some 30 different proteins were oriented in the ribonucleoprotein complex. ERBB-3 binding protein 1 (spot 20) may participate in ribosome assembly and promote cell proliferation and expanding organ growth; its expression was upregulated in normal water conditions but downregulated under drought stress. Similar to $50 \mathrm{~S}$ ribosomal proteins, ribonucleoproteins

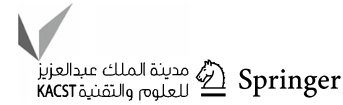




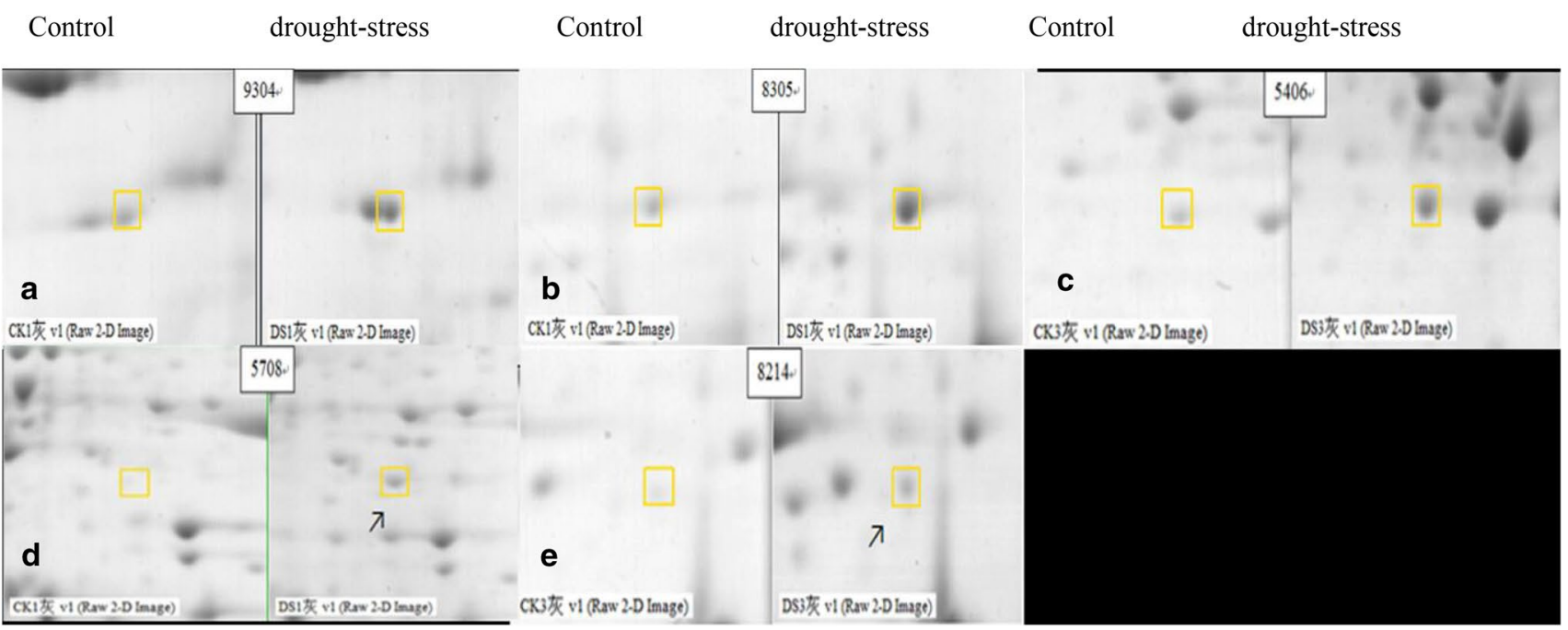

Fig. 3 Five differentially expressed protein spots between control and drought stress-treated sample were selected to be identified by MALDI-TOF/TOF. The boxes represent positions of differential spots on 2-DE images. Compared to control sample (left), those protein

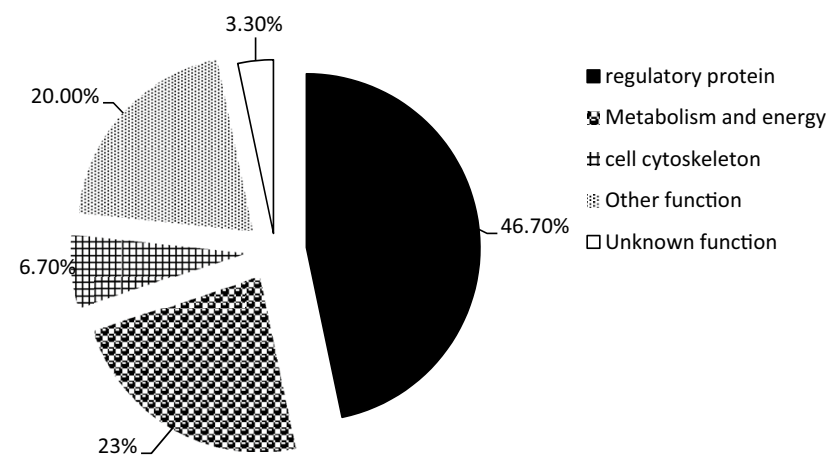

Fig. 4 Classification of identified leaf proteins with changed abundance under drought into functional groups. The functional category distribution of the 30 identified proteins in faba bean. a Regulatory protein; b metabolism and energy; c cell cytoskeleton; d other function; e unknown function

(spot 3) were also involved in protein translation and synthesis; their expression increased under drought stress, it showed that drought stress promotes the protein synthesis system. A similar conclusion has been drawn that expression of rice ribosomal proteins was induced in adverse environments, such as high and low temperature (Kim et al. 2004). Heat shock proteins had characteristics of molecular chaperones and stabilized undenatured proteins and assisted in protein refolding under stress conditions. So that they could play a crucial role in protecting plants against stress by reestablishing normal protein conformation and thus cellular homeostasis. Hsps have been induced under various stress conditions (Wang et al. 2004). In this study, three heat shock spots of drought stress sample (right) were deepen in $\mathbf{a}, \mathbf{b}, \mathbf{c}$; there are two protein spots were new-induced expression in drought-stress samples in $\mathbf{d}, \mathbf{e}$

proteins (Hsp) (spots 9, 10 and 11) we found, which had relatively reduced expression under drought stress, indicated that transport and new synthesis of peptides were decreased, maybe as a result of drought stress inhibiting protein synthesis. Chitinase was an important part of the plant defense system, which played an important role in stress resistance, bacterial resistance and resistance to pests (Cohen-Kupiec and Chet 1998; Gadelhak et al. 2004; Kalyani et al. 2013); spot 27 (class Ia chitinase) expression was upregulated proteins in this research.

\section{Metabolism and energy}

The second type of protein was those involved in metabolism and energy (23.3\%). Being the most abundant proteins in leaf tissue, RuBisCO subunits have reported to be susceptible to fragmentation under drought stress. In those differentially expressed proteins related to metabolism and energy, ribulose-1, 5-bisphosphate carboxylase/oxygenase (RuBisCO) was the enzyme with the highest levels in plant leaves. RuBisCO was a kind of bifunctional enzyme and key to the speed of photosynthesis; it could catalyze carboxylation and oxygenation, playing an important role in the Calvin cycle (Parry et al. 2002; Andersson and Backlund 2008). In this research, the putative RuBisCO subunit binding protein alpha subunit (spot 8) we found might be a RuBisCO fragment and had its expression quantity cut under drought stress. The faba bean leaf photosynthetic rate might reduce under drought stress because of RuBisCO activity declined. In the report, $\mathrm{RuBisCO}$ expression in leaves was reduced under drought stress, and it was the main cause of declining 


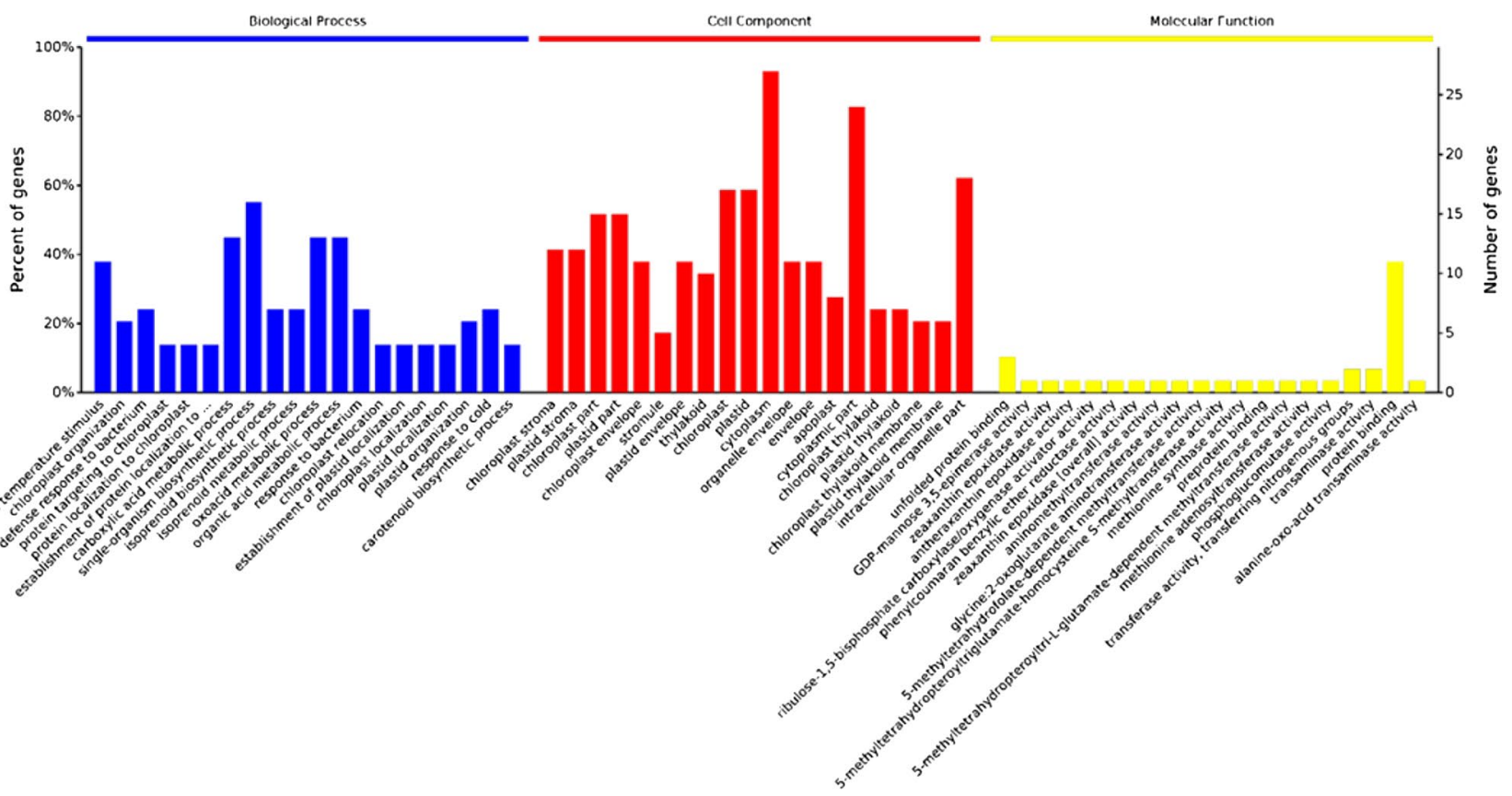

Fig. 5 Gene ontology enrichment analysis of differently abundant proteins. The first part is biologic process, the second part is cell process and the last part is molecular function. The smaller the value of the $p$ value, the higher the significance. For the sake of intuition, a negative and log conversion of the $p$ value, the higher the column, the more obvious the easier to visualize. The gene ontology enrichment analysis of differently abundant proteins. a Biological process-A-1 response to temperature stimulus; A-2 chloroplast organization; A-3 defense response to bacterium; A-4 protein targeting to chloroplast; A-5 protein locatization th chloroplast; A-6 establishment of protein localization to....; A-7 carboxylic acid metabolic process; A-8 singleorganism biosynthetic process; A-9 isoprenoid biosynthetic process; A-10 isoprenoid metabolic process; A-11 oxoacid metabolic process; A-12 organic acid metabolic process; A-13 response to bacterium; A-14 chloroplast relocation ; A-15 establishment of plastid localization; A-16 chloroplast localization; A-17 plastid localization; A-18 plastid organization; A-19 response to cold; A-20 carotenoid biosynthetic process. b Cell component-B-1 chloroplast stroma; B-2 plastid stroma; B-3 chloroplast part; B-4 plastid part; B-5 chloroplast envelope; B-6 stromule; B-7 plastid envelope; B-8 thylakoid;B-9

photosynthetic rate. The accumulation of amino acids can reduce plant osmotic potential and enhance the capacity of plants to absorb water in soil moisture (Good and Zaplachinski 1994; Simon-Sarkadi et al. 2005). Similar to this result, the decreasing content in Rubisco binding protein at the leaf level had previously reported in legume under drought (Aranjuelo et al. 2011; Zadražnik et al. 2017).

Glutamate-glyoxylate aminotransferase (GGAT, spot 19) is a key photorespiration enzyme during photosynthesis, involved in carbon fixing, carbon metabolism, the catalytic serine and glyoxylate ammonia reaction of glycine and eventually generating hydroxyl pyruvic acid; at the same time, it plays an important role in growth, development and stress resistance of plants (Igarashi et al. 2006). Chlorophyll is chloroplast; B-10 plastid; B-11 cytoplasm; B-12 organelie envelope; B-13 envelope; B-14 apoplast; B-15 cytoplasmic part; B-16 chloroplast thylakoid; B-17 plastid thylakoid; B-18 chloroplast thylakoid membrane; B-19 plastid thylakoid membrane; B-20 intracellular organelle part; $\mathbf{c}$ Molecular function- $\mathrm{C}-1$ unfolded protein binding; C-2 GDP-mannose 3,5-epimerase activity; C-3 zeaxanthin epoxidase activity; C-4 antheraxanthin epoxidase activity; C-5 ribulose-1,5-bisphosphate carboxylase/oxygenase activator activity; C-6 phenylcoumaran benzylic ether reductase activity; C-7 zeaxanthin epoxidase [overall] activity; C-8 aminonethyltransferase activity; C-9 glycine: 2-oxoglutarate aminotransferase activty; C-10 5-methyltetrahydrofolate-dependent methyltransferase activity; C-11 5-methyltetrahydropteroyltriglutamate-homocysteine S-methyltransferase activity; C-12 methlonine adenosyltransferase activity; C-13 preprotein binding; C-14 5-methyltetrahydropteroyltri-L-glutamate-dependent methyltransferase activity; C-15 methionine adenosylttansferase activity; C-16 phosphoglucomutase activity; C-17 transferase activity, transferring nitrogenous groups; $\mathrm{C}-18$ transaminase activity; C-19 protein binding; C-20 alanine-oxo-acid transaminase activity

an important pigment involved in photosynthesis in plant chloroplasts. GGAT mutation of plants showed phenomena such as slow growth and lower chlorophyll content (Versluse et al. 2007); in this study, GGAT (spot 19) expression was upregulated, illustrating that water stress increased serine and glyoxylic acid in plant metabolism of ammonia and light response, causing chlorophyll reduction of plants under drought stress. On the other hand, the results verified that faba bean plants had grown slowly and leaf chlorophyll content was reduced under drought stress. The main biological and biochemical function of D-alanyl-D-alanineendopeptidase (spot 6) is the biosynthesis of the secondary metabolites carotenoids to mitigate and damage against reactive oxygen species, at the same time as the pigment

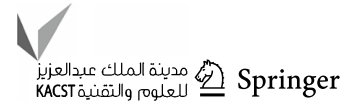


involved in plant photosynthesis, chlorophyll, protection from drought damage. Moreover, phosphoglucomutase (spot 14) showed lower expression under drought stress, so that drought stress inhibits leaf sugar metabolism of faba bean and leads to increased soluble sugar content, thus enhancing the plant's drought resistance, an essential reason for " $\mathrm{Ga}$ da dou" faba bean showing strong drought resistance. In addition, 5-methyltetrahydropteroyltriglutamate-homocysteine methyltransferase-like (spot 22) is an enzyme that catalyzes the chemical reaction involved in the synthesis of a number of important secondary metabolites in plants. It shows that in plants with abiotic tolerance ability, an important signal transduction material is formed under the action of methyltransferase (Zhang et al. 2012), presumably in response to drought stress after a methyl transfer reaction, thus improving the essential drought-resistant ability of "Ga da dou".

\section{Cytoskeleton protein}

The third type is cytoskeleton proteins (3.1\%), which were important in maintaining cell shape and internal structure in response to low temperature, salt and drought stress. The tubulin was a basic component of cytoskeleton in all eukaryotic cells and decreased under drought stress in this study. Microtubules were a major structural component of the cytoskeleton and participate in cell division, intracellular transport, and cell morphogenesis (Alieva 2014); it could be related to dynamic reorganization of microtubules and polymers of $\alpha$ - and $\beta$-tubulin heterodimers (Sheoran et al. 2014). It showed that tubulin alpha-2 chain (spot 13) expression was downregulated under drought stress, so we speculate that the drought resistance of the cultivar "Ga da dou" may be based on expression changes of cytoskeleton proteins, by regulating cell size to adjust osmotic pressure and showing strong drought resistance. Ndimba et al. (2005) also reported a decrease in abundance of tubulin beta chain in Arabidopsis under osmotic stress. At the same time, broken cytoskeletal structure could be a reason for the declining leaf conductivity and explain the physiological indices in determining the cause of the decrease in leaf conductivity.

\section{Other functional proteins}

The fourth type is other functional proteins (20.0\%); spots 1, 7 and 12 were identified as hypothetical proteins. Spot 19 was identified as glutamine synthetase, involved in nitrogen metabolism enzyme, which can enhance photorespiration to improve the drought and cold resistance of rice; some research about rice root drought and cold resistance has been reported (Hoshida et al. 2000; Cui et al. 2005). The expression of this protein could improve the resistance of plants; the function of the protein in drought resistance and its effects still need further study and research.

\section{Unknown proteins}

The fifth type is proteins of unknown function (3.3\%), spot 21 (GI number 217072432), the sequence of which is homologous to Medicago truncatula (alfalfa). In the mass spectrum identification database, no reliable results were retrieved, so that the database may not contain this protein.

\section{Conclusions}

In this study, the abundance of proteins in faba bean under drought stress conditions in Qinghai-Tibet Plateau of China was identified at first time. 25 proteins were clearly downregulated and five proteins were upregulated in 30 differentially expressed proteins. Regulatory proteins and metabolism within energy metabolism proteins hold very important positions in five types of functional category. Under drought stress, regulatory proteins (heat shock protein 81-2) could ease of denatured protein concentration, stimulate new peptides further folds into a functional protein, assist the degradation of misfolded proteins to resist drought stress. The downregulated proteins mainly regulate the balance of stress defense, energy metabolism, cytoskeleton and oxidation, and the upregulated proteins regulate proteins folding and aggregation and photosynthesis system. The results suggest that proteins related to the cell defense pathways are modulated by overlapping signaling mechanisms, which provided information for overall understanding and engineering strategies to improve drought tolerance of faba bean in Qinghai-Tibet Plateau of China.

Acknowledgements This work was supported by the National Natural Science Foundation of China (31460377) and China Agriculture Research System (CARS-09-G4). Part of the research was finished in the Open Project of the State Key Laboratory of Plateau Ecology and Agriculture, Qinghai University.

\section{Compliance with ethical standards}

Conflict of interest The authors declare that they have no conflict of interest.

Open Access This article is distributed under the terms of the Creative Commons Attribution 4.0 International License (http://creativeco mmons.org/licenses/by/4.0/), which permits unrestricted use, distribution, and reproduction in any medium, provided you give appropriate credit to the original author(s) and the source, provide a link to the Creative Commons license, and indicate if changes were made. 


\section{References}

Abdelmula AA, Link W, Kittlitz EV, Stelling D (1999) Heterosis and inheritance of drought tolerance in faba bean, Vicia faba L. Plant Breed 118(6):485-490

Alam I, Akhtar SS, Kim KH, Yang JK, Choi MS, Lee BH (2010) Proteome analysis of soybean roots subjected to short-term drought stress. Plant Soil 333(1/2):491-505

Alieva IB (2014) Role of microtubule cytoskeleton in regulation of endothelial barrier function. Biochemisty (Moscow) 79(9):964-975

Amede T, Kittlitz E, Schubert S (1999) Differential drought responses of faba bean (Vicia faba L.) inbred lines. J Agron Crop Sci 183(1):35-45

Andersson I, Backlund A (2008) Structure and function of Rubisco. Plant Physiol Biochem 46(3):275-291

Aranjuelo I, Molero G, Erice G, Avice JC, Nogués S (2011) Plant physiology and proteomics reveals the leaf response to drought in alfalfa (Medicago sativa L.). J Exp Bot 62(1):111-123

Awasthi R, Kaushal N, Vadez V, Turner NC, Berger J, Siddique KHM, Nayyar H (2014) Individual and combined effects of transient drought and heat stress on carbon assimilation and seed filling in chickpea. Funct Plant Biol 41(7):1148-1167

Azooz MMY (2010) Evaluation of heat shock and salicylic acid treatments as inducers of drought stress tolerance in Hassawi wheat. Am J Plant Physiol 5(2):56-70

Banci L, Bertini I, Simone CB, D'Alessandro A, Jaiswal D, Marzano V, Neri S, Ronci M, Urbani A (2011) Copper exposure effects on yeast mitochondrial proteome. J Proteom 74(4):2522-2535

Boschin G, Arnoldi A (2011) Legumes are valuable sources of tocopherols. Food Chem 127(11):1199-1203

Bradford MM (1976) A rapid and sensitive method for quantitation of microgram quantities of protein utilizing principle of protein-dye binding. Anal Biochem 72(3):248-254

Broughton WJ, Hernandez G, Blair M, Beebe S, Gepts P, Vanderleyden J (2003) Beans (Phaseolus spp.) —model food legumes. Plant Soil 252(5):55-128

Celis JE, Gromov P (1999) 2D protein electrophoresis: can it be perfected? Curr Opin Biotechnol 10(1):16-21

Ceccarelli S (2010) Drought and drought resistance. Encycl Biotechnol Agric Food 1(5):205-207

Chaves MM, Flexas J, Pinheiro C (2009) Photosynthesis under drought and salt stress: regulation mechanisms from whole plant to cell. Ann Bot 103(4):551-560

Chen Q, Zhang MD, Shen SH (2011) Comparison of protein extraction methods suitable for proteomics analysis in seedling roots of Jerusalem artichoke under salt $(\mathrm{NaCl})$ stress. Afr J Biotech 10(39):7650-7657. https://doi.org/10.5897/AJB10.605

Cohen-Kupiec R, Chet I (1998) The molecular biology of chitin digestion. Curr Opin Biotechnol 9(3):270-277

Cramer GR, Urano K, Delrot S, Pezzotti M, Shinozaki K (2011) Effects of abiotic stress on plants: a systems biology perspective. BMC Plant Biol 11(4):163-177

Cui S, Huang F, Wang J, Ma X, Cheng Y, Liu J (2005) A proteomic analysis of cold stress responses in rice seedlings. Proteomics 5(12):3162-3172

Das A, Eldakak M, Paudel B, Kim DW, Hemmati H, Basu C, Rohila JS (2016) Leaf proteome analysis reveals prospective drought and heat stress response mechanisms in soybean. Bio Med Res Int. https://doi.org/10.1155/2016/6021047

Farooq M, Wahid A, Kobayashi N, Fujita D, Basra SMA (2009) Plant drought stress: effects, mechanisms and management. Agron Sustain Dev 29(1):185-212

Farooq M, Siddique KHM, Alghamdi SS, Gogoi N, Baroowa B, Bharadwaj N, Barthakur S (2017) Drought stress in grain legumes during reproduction and grain filling. J Agric Crop Sci 203(4):81-102

Gadelhak GG, Eltarabily KA, Alkaabi FK (2004) Insect control using chitinolytic soil actinomycetes as biocontrol agents. Int J Agric Biol 7(4):627-633

Ge P, Hao PC, Cao M, Guo GF, Li DW, Saminathan S, Li XH, Yan X, Xiao JT, Ma WJ (2013) iTRAQ based quantitative proteomic analysis reveals new metabolic pathways of wheat seedling growth under hydrogen peroxide stress. Proteomics 13(20):3046-3058

Good AG, Zaplachinski ST (1994) The effects of drought stress on free amino acid accumulation and protein synthesis in Brassica napus. Physiol Plant 90(1):9-14

Görg A, Weiss W, Dunn MJ (2004) Current two-dimensional electrophoresis technology for proteomics. Proteomics 4(12):3665-3685

Gupta N, Thind SK, Bains NS (2014) Glycine betaine application modifies biochemical attributes of osmotic adjustment in drought stress wheat. Plant Growth Regul 72(3):221-228

Hoshida H, Tanaka Y, Hibino T, Hayashi Y, Tanaka A, Takabe T, Takabe T (2000) Enhanced tolerance to salt stress in transgenic rice that overexpresses chloroplast glutamine synthetase. Plant Mol Biol 43(1):103-111

Hou WW, Zhang XJ, Shi JB, Liu YJ (2015) Genetic diversity analysis of faba bean (Vicia faba L.) germplasms using sodium dodecyl sulfate-polyacrylamide gel electrophoresis. Genet Mol Res 14(4):13945-13953

Igarashi D, Tsuchida H, Miyao M, Obsumi C (2006) Glutamate: glyoxylate aminotransferase modulates amino acid content during photorespiration. Plant Physiol 142(3):901-910

Jaiswal DK, Mishra P, Subba P, Rathi D, Chakraborty S, Chakraborty N (2014) Membrane-associated proteomics of chickpea identifies Sad1/UNC-84 protein (CaSUN1), a novel component of dehydration signaling. Sci Rep 4:4177. https://doi.org/10.1038/srep04177

Kalyani P, Pooja BM, Farid W (2013) Overexpression of a chitinase gene in transgenic peanut confers enhanced resistance to major soil borne and foliar fungal pathogens. J Plant Biochem Biotechnol 2:222-233. https://doi.org/10.1007/s13562-012-0155-9

Kanehisa M, Araki M, Goto S, Hattori M, Hirakawa M, Itoh M, Katayama T, Kawashima S, Okuda S, Tokimatsu T, Yamanishi Y (2008) KEGG for linking genomes to life and the environment. Nucleic Acids Res 36(2):480-484. https://doi.org/10.1093/nar/gkm882

Katayama H, Nagasu T, Oda Y (2001) Improvement of in-gel digestion protocol for peptide mass fingerprinting by matrix-assisted laser desorption/ionization time-of-flight mass spectrometry. Rapid Commun Mass Spectrom 15(16):1416-1421

Khan HR, Paull JG, Siddique KHM, Stoddard FL (2010) Faba bean breeding for drought-affected environments: a physiological and agronomic perspective. Field Crops Res 115(3):279-286

Kim KY, Park SW, Chung YS, Chung CH, Kim J, Lee JH (2004) Molecular cloning of low-temperature-inducible ribosomal proteins from soybean. J Exp Bot 399(55):1153-1155

Kosová K, Vitámvás P, Prášil IT, Renaut J (2011) Plant proteome changes under abiotic stress-contribution of proteomics studies to understanding plant stress response. J Proteom 74(8):1301-1322

Li P, Hou WW, Liu YJ (2014) Effects of drought stress on morphological indexes and protective enzymes activity of leaf in faba bean (Vicia faba L.) seedling. Southwest China J Agric Sci 27(3):1029-1036

Li P, Zhang YX, Liu YJ (2015) Drought tolerance in different faba bean materials at seed germination stage under peg stress in northwest of China. J Sichuan Agric Univ 33(3):251-264

Manaa A, Ahmed HB, Valot B, Faurobert M (2011) Salt and genotype impact on plant physiology and root proteome variations in tomato. J Exp Bot 62(8):2797-2813

Martínez JP, Silva HFLJ, Ledent JF, Pinto M (2007) Effect of drought stress on the osmotic adjustment, cell wall elasticity and cell

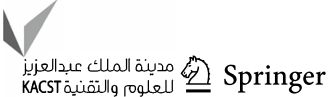


volume of six cultivars of common beans (Phaseolus vulgaris L.). Eur J Agron 26(7):30-38

Millar AH, Sweetlove LJ, Giege P, Leaver CJ (2001) Analysis of the Arabidopsis mitochondrial proteome. Plant Physiol 127(10):1711-1727

Mittler R, Zilinskas BA (1994) Regulation of pea cytosolic ascorbate peroxidase and other antioxidant enzymes during the progression of drought stress and following recovery from drought. Plant $\mathbf{J}$ 5(1):397-405

Ndimba BK, Chivasa S, Simon WJ, Slabas AR (2005) Identification of Arabidopsis salt and osmotic stress responsive proteins using twodimensional difference gel electrophoresis and mass spectrometry. Proteomics 5(3):4185-4196

Owiti J, Grossmann J, Gehrig P, Dessimoz C, Laloi C, Hansen MB, Gruissem W, Vanderschuren H (2011) iTRAQ-based analysis of changes in the cassava root proteome reveals pathways associated with post-harvest physiological deterioration. Plant J 67(1):145-156

Pandey A, Chakraborty Datta A, Niranjan Chakraborty (2008) Proteomics approach to identify dehydration responsive nuclear proteins from chickpea (Cicer arietinum L.). Mol Cell Proteom 7(1):88-107

Parry MAJ, Andralojc PJ, Khan S, Lea PJ, Keys AJ (2002) Rubisco activity: effects of drought stress. Ann Bot 89(6):833-839

Sengupta D, Kannan M, Reddy AR (2011) A root proteomics-based insight reveals dynamic regulation of root proteins under progressive drought stress and recovery in Vigna radiata (L.) Wilczek. Planta 233(6):1111-1127

Shah S, Lee YJ, Hannapel D, Rao A (2011) Protein profiling of the potato petiole under short day and long day photoperiods. J Proteom 74(2):212-230

Sheoran IS, Koonjul P, Attieh J, Saini HS (2014) Water-stress-induced inhibition of tubulin gene expression during growth, and its implications for reproductive success in rice. Plant Physiol Biochem 80(12):291-299

Simon-Sarkadi L, Kocsy G, Varhegyi A, Galiba G, de Ronde JA (2005) Genetic manipulation of proline accumulation influences the concentrations of other amino acids in soybean subjected to simultaneous drought and heat stress. J Agric Food Chem 53(19):7512-7517
Subba P, Kumar R, Gayali S, Shekhar S, Parveen S, Pandey A (2013) Characterisation of the nuclear proteome of a dehydration-sensitive cultivar of chickpea and comparative proteomic analysis with a tolerant cultivar. Proteomics 13(4):1973-1992

Tran LSP, Mochida K (2010) Identification and prediction of abiotic stress responsive transcription factors involved in abiotic stress signaling in soybean. Plant Signal Behav 3(5):255-257

Turner NC, Davies SL, Plummer JA, Siddique KM (2005) Seed filling in grain legumes under water deficits with emphasis on chickpea (Cicer arietinum L.). Adverse Agron 11(87):211-225

Versluse PE, Kim YS, Zhu JK (2007) Altered ABA, proline and hydrogen peroxide in an Arabidopsis glutamate: glyoxylate aminotransferase mutant. Plant Mol Biol 64(12):205-217

Wang W, Vinocur B, Shoseyov O, Altman A (2004) Role of plant heat-shockproteins and molecular chaperones in the abiotic stress response. Trends Plant Sci 9(6):244-252

Watson BS, Asirvatham VS, Wang LJ, Sumner LW (2003) Mapping the proteome of barrel medic (Medicago truncatula). Plant Physiol 131(3):1104-1123

Xu C, Wu XQ (2016) Physiological and proteomic analysis of mycorrhizal pinus massoniana inoculated with Lactarius insulsus under drought stress. Russ J Plant Physiol 63(5):709-717

Zadražnik T, Egge-Jacobsen W, Meglič V, Šuštar-Vozlič J (2017) Proteomic analysis of common bean stem under drought stress using in-gel stable isotope labeling. J Plant Physiol 209(2):42-50

Zhang KR, McKinlay C, Hocart CH, Djordjevic MA (2006) The medicago truncatula small protein proteome and peptidome. J Proteome Res 5(12):3355-3367

Zhang XL, Zhou J, Han Z, Shang Q, Wang ZG, Gu XH, Ge CL (2012) Active methyl cycle and transfer related gene expression in response to drought stress in rice leaves. Rice Sci 19(2):86-93. https://doi.org/10.1016/S1672-6308(12)60026-2

Zhang M, Jin ZQ, Zhao J, Wu FB (2015) Physiological and biochemical responses to drought stress in cultivated and Tibetan wild barley. Plant Growth Regul 75(1):567-574

Zhu JK (2002) Salt and drought stress signal transduction in plants. Annu Rev Plant Biol 53(2):247-273 